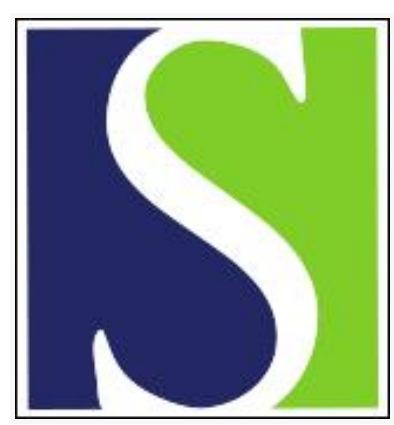

Scand J Work Environ Health 2002;28(1):1-4

https://doi.org/10.5271/sjweh.639

Issue date: Feb 2002

The psychosocial work environment and health - what do we know and where should we go?

by Kompier $M$

Affiliation: Radboud University Nijmegen, Deparment of Work and Oragnizational Psychology, PO Box 9104, 6500 HE Nijmegen, The Netherlands. kompier@psych.kun.nl

The following articles refer to this text: 2004;30(2):81-83;

2012;38(3):238-246; 2012;38(3):187-192

Key terms: editorial; health; psychosocial work environment

This article in PubMed: www.ncbi.nlm.nih.gov/pubmed/11871847

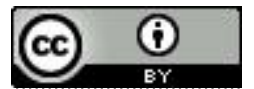




\section{The psychosocial work environment and health — what do we know and where should we go?}

In 1981 the Swedish scientist Bertil Gardell (1) defined five central requirements for the psychosocial work environment. "Work should be arranged in a way which allows the individual worker to influence his own working situation, working methods and pace. Work should be arranged in a way which allows for an overview and understanding of the work process as a whole. Work should be arranged in a way which gives the individual worker possibilities to use and develop all his human resources. Work should be arranged in a way that allows for human contacts and co-operation in the course of work. Work should be arranged in a way which makes it possible for the individual worker to satisfy time claims from roles and obligations outside work, e.g. family, social and political commitments, etc. [p 73]."

Twenty years have passed since Gardell presented his requirements. In the meantime we have witnessed the development of a new academic discipline, "occupational health psychology", thousands of "psychosocial" studies, and many theories in the field of occupational stress and well-being, job satisfaction, and job design. But Gardell's five requirements still stand. What we have learned in the interim is that healthy work presupposes appropriate levels of psychological job demands, job variety, autonomy, and support from others. We have also learned that stress and motivation can be regarded as two sides of the same coin. If work provides the right mix of work characteristics - that is, high but not too high demands, enough but not too much control and support, and so forth — work stimulates motivation and mental health as well as productive performance. When work does not provide a proper configuration of work characteristics (eg, psychological demands that are too low or too high, responsibility that is too little or too much), it may provoke stress reactions. In a process of chronic exposure to such risk factors and insufficient recovery, the reactions (behavioral, psychological, physiological) may, in the long run, lead to serious illness. As in other occupational health areas, individual characteristics and behavioral styles of employees play a role in the complex and dynamic interplay between combinations of work characteristics, work behavior, and health outcomes.

To narrow the gap between theory and research on occupational stress, on one hand, and policy and practice, on the other, has always been an endeavor of scholars like Bertil Gardell and Lennart Levi. Their work has influenced national and European legislation regarding psychosocial factors at work. Several European countries have introduced legislation in this respect. The most prominent legal regulation on the quality of worklife is the European framework directive on health and safety at work (89/391/EEC; 1993). This directive applies to psychosocial job design and work-related well-being. More recently, the European Parliament has taken a clear and comparable stand. It "considers that work must be adapted to people's abilities and needs and not vice-versa, and notes that by preventing a disparity from arising between the demands of work and the capacities of the workers, it is possible to retain employees until retirement age; considers that new technologies should be used in order to achieve these aims; draws attention to the problems resulting from a lack of autonomy at the workplace, monotonous and repetitive work and work with a narrow variety of content, all features which are typical of women's work in particular, and calls attention to be paid to the importance of ergonomics to the improvement of health and safety conditions at the workplace" (Resolution A4-0050/99, 25th February 1999).

Such legislation is needed because occupational stress and work-related fatigue have become major problems in today's organizations. There are also strong indications that stress and fatigue at work are on the increase. According to a recent study among 21500 European employees, the most common work-related health problems are backache $(33 \%)$, stress $(28 \%)$, and fatigue $(23 \%)(2)$. The same study showed that, today, most European employees work at very high speeds or under tight deadlines more than $50 \%$ of the time. These percentages are higher when compared with those of 1990 and 1995. As most workers are nowadays employed in the service sector, this workpace is primarily dependent on direct demands from clients (67\%) and colleagues (48\%). Of the employees who continuously work tight deadlines, $40 \%$ reports 
stress and $42 \%$ reports backache (against $20 \%$ and 27\%, respectively, of the employees who never work under tight deadlines). According to a study by Bond et al (3), involving a national representative sample of 3000 American employees, $29 \%$ of the respondents found it somewhat or very likely that they would lose their current job in the next couple of years. Twenty-six percent felt "emotionally drained from their work", and $26 \%$ felt "burned out and stressed by their work". The latter two scores represent two research lines that recently gained prominence in occupational health psychology: research into emotional work demands and burnout and research into the work-home interface. The latter concept refers to the positive or negative impact of the work situation on the nonwork area and vice versa.

Over the last few decades the occupational arena has undergone remarkable changes. These changes have certainly influenced the psychosocial work environment and, thereby, affected stress at work. Among these developments are the increased utilization of information and communication technology, the rapid expansion of the service sector, the globalization of the economy, the changing structure of the workforce (more female, fewer young, and more highly educated employees), the increasing flexibilization of work, the creation of the 24-hour economy, and the utilization of new production concepts (eg, team-based work, telework, downsizing, outsourcing, subcontracting). Compared with workers 20 years ago, modern employees increasingly work in offices (and less in industry or agriculture), with information or clients (and less with tangible objects), in teams (and less in isolation), and with less job security. The most striking development is the changing nature of work itself and its increased psychosocial workload. Largely, work has changed from manual to mental in nature. Today, for many employees, work primarily poses mental and emotional demands. This change explains why mismatches between work and the worker are increasingly manifested in psychological dysfunctioning and psychosomatic diseases.

So, what is known with respect to the psychosocial work environment and health? We do know (i) that occupational stress is a major problem in modern organizations, for both individual employees and for management, (ii) which factors in work are major risk factors for stress and its consequences for ill health, and (iii) that there is national and international legislation that underlines the importance of risk assessment and risk management (primary prevention). "There is a wealth of scientific data on work stress, its causes and effects, and some of the mechanisms underpinning the relationships among these [p 10]" (4). We do have good general models on the relations between these work factors, personal characteristics, and short- and long-term consequences for the individual and the organization (5).

Where should research in this domain be heading? Before we try to answer this question, we should first discuss which directions we prefer not to be chosen. I would like to take the following three interrelated positions: (i) more general research is not needed, (ii) further expansion of the number of studies based on cross-sectional study designs and on employees' self-reports has little added value, and (iii) we should not try to compensate for weak study designs by increasing the number of sophisticated statistical analyses.

With respect to the first point ("more general research is not needed", see also reference 4, p10), I can be short. I argue that alternative general "work, stress and health" models are often variations of existing models: old wine in new bottles. Enough general knowledge already exists, and we do not need "more of the same".

I shall discuss the two other points in more detail here. General stress models are often tested in a crosssectional study design. Already in 1987, Kasl (6) emphasized the pitfalls of this type of data collection: "The sheer volume of studies which has been generated by cross-sectional retrospective designs, in which only self-reports of independent, intervening and outcome variables are correlated to each other, is so enormous that they have created their own standard of 'acceptable' methodology. Journal editors (presumably quite aware of methodological limitations) may be reluctant to put a moratorium on a methodology which was acceptable only yesterday [p 308]." Correlation is no causation. Kasl points at the fact that a statistical association between "high perceived work demands" and "self-reported health complaints" is usually interpreted as "bad work causes bad health" ("normal causation", from left to right). However, people with health complaints may have more problems in coping with their work demands and accordingly report higher demands ("reverse causation", from right to left). Both mechanisms may play a role ("reciprocal relations"). A third variable, such as a personality trait, may "cause" both. The association may even be artificial and trivial and a matter of content overlap (work demands: "my work is often very demanding"; health complaints: "I am often tired"). 
Fifteen years later, papers of this type are still submitted, and many of them are published. What do many authors do? Usually in the discussion section of the manuscripts, by way of cliché, the following two standard remarks are made: (i) "this research was cross-sectional and based on self-reports" and (ii) "therefore we cannot draw causal inferences". In the remainder of the text authors often tend to ignore these restrictions, stating that one variable "leads to", "has effect on", "causes", or "predicts" the other. What the researchers do not admit is that, given the design of the study, it is possible that all arrows in their research model "point from right to left" instead of "from left to right". In fact, each model that is empirically tested with the use of crosssectional data is equivalent to the one in which all arrows are reversed.

Third, and related to this second point, the tendency to "correct" for weak study designs by increasing the number of sophisticated statistical analyses can be criticized. It is a popular myth that sophisticated statistical analyses may compensate for weak study designs. Again, what do many authors do? Without providing a simple correlation table and a comparison of the average scores on the various scales with reference scores, a lot of "fashionable high brow" statistics are presented. Many statistical packages are now easily accessible and user friendly, and sometimes the reader gets the impression that little theoretical, methodological, and statistical knowledge is required "to try them". In addition methodological semantics has contributed to this status. Structural equation modeling, for example, popular among psychological stress researchers, was originally labeled "causal modeling" (7). We do need to bear in mind that it is the way that the study is designed and the way that the data are collected, and not the statistical tools, that may permit us to make (causal) inferences. Causality presupposes that the following four requirements are met: statistical association, temporal ordering, exclusion of plausible rival hypotheses, and theoretical plausibility (8). Better knowledge in occupational health psychology is much more likely to come about from simple analyses of good data than from increasingly sophisticated analyses of poor data. (See reference 6, p 210). This is not to say that, in the field of work, stress and health, cross-sectional designs are inherently of little scientific value. Whether or not this is true depends on the question under study. Prevalence questions may well be answered with such designs; causality questions cannot.

Now that I have stressed where we should not go, in which directions do we think that research in the field of work, stress and health should go? In order to understand the complex and dynamic interplay better between work characteristics, personal characteristics, behavior, and health outcomes, there is a need for (i) better [ie, longitudinal, (quasi)experimental] designs and (ii) better data (triangulation). Through these designs and data, and in addition to the existing general stress models, we should (iii) focus more on more-specific "how questions" and microprocesses. And (iv) there is a need to transform the existing body of knowledge in prevention and intervention research.

Longitudinal research, preferably using a full panel design that measures both the "independent" and "dependent" variables at various theoretically chosen time points, provides the opportunity to investigate three types of causation: normal, reversed and reciprocal. We should bear in mind that longitudinal designs have their problems too (eg, attrition, the process under study may have started before the chosen time span: there is always a "T-0 minus 1"), and applying them is in itself no guarantee for making causal inferences.

More-detailed (both experimental and quasi-experimental) studies into work-person-stress-health etiology may shed more light on various "links and loops in the chain". Such (quasi)experimental studies may take place in both laboratory and field settings. We can expect that adequate research programs will increasingly combine laboratory and field studies.

It is important that future research combine psychological, behavioral, and physiological measures. Leading principles in this respect are triangulation, plausible rival hypotheses, and converging and diverging evidence (9). Physiological measures and measures of cognitive functioning are needed to understand better the various pathways between the exposure to certain work characteristics and health outcomes.

Longitudinal and more experimental studies could focus on "how questions" and microprocesses. Some examples of "how questions" are "How (ie, via which mechanisms and through which links) do work characteristics influence health?" "How does actual work behavior and situation-specific coping influence this relation?" "How is actual work behavior influenced in such a process?" Such better-designed studies may also focus on the positive effects of work on health and performance. Preferably, they will not only treat personality factors as independent or moderator variables, but also as dependent variables. 
Finally, there is a strong need for well-designed and well-implemented prevention and intervention studies. What is the current status with respect to prevention and intervention? Such programs are predominantly reactive and aimed at individuals. This is surprising and disappointing in view of all that is known on the relationships between the psychosocial work environment and health and in view of legislation on work conditions that emphasizes primary prevention. More recently, though, there has been a clear increase in welldocumented intervention studies on the psychosocial work environment that aim at improving job design through improving job features. Evidence is growing that interventions do have the potential to be beneficial for both the employee and the company, if they combine a thorough risk assessment, measures that include both the task and the social work environment, ways to deal with stress, and also a careful approach to implementation (10).

The Scandinavian Journal of Work, Environment \& Health stimulates and invites research in these directions.

\section{References}

1. Gardell B. Psychosocial aspects of industrial product methods. In: Levi L, editor. Society, stress and disease; vol 4. Oxford: Oxford University Press, 1981:65-75.

2. Merllié D, Paoli P. Ten years of working conditions in the European Union. Dublin: European Foundation for the Improvement of Living and Working Conditions, 2000.

3. Bond T, Galinsky E, Swanberg JE. The 1997 national study of the changing workforce. New York(NK): Families and Work Institute, 1998.

4. Cox T, Griffiths A, Rial-Gonzalez R. Research on work-related stress. Bilbao: European Agency for Safety and Health at Work, 2000.

5. Kompier M. Job design and well-being. In: Schabracq M, Winnubst J, Cooper C, editors. Handbook work and health psychology. Chichester: Wiley. In press.

6. Kasl SV. Methodologies in stress and health: past difficulties, present dilemmas, future directions. In: Kasl SV, Cooper CL, editors. Stress and health: issues in research and methodology. Chichester: John Wiley, 1987:307-18.

7. Brannick M. Critical comments on applying covariance structure modelling. J Organ Behav 1995;16:201-13.

8. Taris TW. A primer in longitudinal data analysis. London: Sage, 2000.

9. Kompier M, Kristensen TS. Organizational work stress interventions in a theoretical, methodological and practical context. In: Dunham J, editor. Stress in the workplace: past, present and future. London: Whurr Publishers, 2000: 16490 .

10. Semmer N. Job stress interventions and organisation of work. In: Quick JC, Tetrick LE, editors. Handbook of occupational health psychology. Washington (DC): American Psychological Association. In press.

\section{Michiel Kompier, Co-editor}

\section{Scandinavian Journal of Work, Environment \& Health}

